\title{
Host gene expression profiling in influenza $A$ virus-infected lung epithelial (A549) cells: a comparative analysis between highly pathogenic and modified $\mathrm{H} 5 \mathrm{~N} 1$ viruses
}

Alok K Chakrabarti, Veena C Vipat, Sanjay Mukherjee, Rashmi Singh, Shailesh D Pawar, Akhilesh C Mishra

\begin{abstract}
Background: To understand the molecular mechanism of host responses to highly pathogenic avian influenza virus infection and to get an insight into the means through which virus overcomes host defense mechanism, we studied global gene expression response of human lung carcinoma cells (A549) at early and late stages of infection with highly pathogenic avian Influenza A (H5N1) virus and compared it with a reverse genetics modified recombinant A (H5N1) vaccine virus using microarray platform.
\end{abstract}

Results: The response was studied at time points 4, 8, 16 and 24 hours post infection (hpi). Gene ontology analysis revealed that the genes affected by both the viruses were qualitatively similar but quantitatively different. Significant differences were observed in the expression of genes involved in apoptosis and immune responses, specifically at $16 \mathrm{hpi}$.

Conclusion: We conclude that subtle differences in the ability to induce specific host responses like apoptotic mechanism and immune responses make the highly pathogenic viruses more virulent.

\section{Background}

Outbreaks of avian influenza A (H5N1) virus, a highly pathogenic avian influenza (HPAI), are considered as a public health risk with pandemic potential [1]. Understanding the pathology, transmission, clinical features and treatments has become necessary for the prevention and management of such outbreaks [2,3]. The mechanisms responsible for the virulence of HPAI viruses in humans are not completely understood. Viral factors are necessary for productive infection but are not sufficient to explain the pathogenesis of HPAI infection in humans $[4,5]$.

It is well recognized that host immunological and genetic factors also play an important role in the pathogenesis of H5N1 viruses in humans [5,6]. Recent studies have shown that the high fatality rate of avian influenza virus infections is a consequence of the complex interaction of virus and host immune responses which include

\footnotetext{
* Correspondence: aloke8@yahoo.com
Microbial Containment Complex, National Institute of Virology, Sus Road,

* Correspondence: aloke8@yahoo.com Pashan, Pune - 411021 India
}

overactive inflammatory response in the form of hypercytokinemia (cytokine storm), that is initiated inside the infected cells or tissue in response to virus replication resulting in excessive cellular apoptosis and tissue damage [7-9]. In vitro, in vivo and clinical studies have suggested that H5N1 viruses are very strong inducers of various cytokines and chemokines [Tumor Necrosis Factor (TNF)-alpha, Interferon (IFN)-gamma, IFN-alpha/ beta, Interleukin (IL)-6, IL-1, MIP-1 (Macrophage Inflammatory Protein), MIG (Monokine Induced by IFNgamma), IP-10 (Interferon-gamma-Inducible Protein), MCP-1 (Monocyte Chemoattractant Protein), RANTES (Regulated on Activation Normal T-cell Expressed and Secreted), IL-8], in both humans and animals [10-12]. However, it has also been reported that preventing cytokine response doesn't prevent H5N1 infection and cell death [13]. Hence, further studies are needed to understand the pathogenesis of $\mathrm{H} 5 \mathrm{~N} 1$ virus infection.

Alveolar epithelial cells and macrophages are the key targets for $\mathrm{H} 5 \mathrm{~N} 1$ virus in the lungs [14]. Using infection in human lung carcinoma cells we analyzed early and 
late host responses at 4, 8, 16 and 24 hours post infection by employing gene expression profiling on a microarray platform. A comparative analysis was thus carried out at different time points post infection between highly pathogenic avian influenza A H5N1 virus (HPAIH5N1), A/Chicken/India/WB-NIV2664/2008(H5N1) and modified recombinant vaccine virus (RG modified H5N1), A/India/NIV/2006(H5N1)-PR8-IBCDC-RG7.

A/Chicken/India/WB-NIV2664/2008 is a recent strain of $\mathrm{H} 5 \mathrm{~N} 1$ of clade 2.2 circulating in chicken population in India [15] and A/India/NIV/2006(H5N1)-PR8-IBCDC-RG7 is a reverse genetics modified virus generated from HPAI, $\mathrm{A} /$ chicken/India/NIV33487/2006 (H5N1) of the same clade [16]. The objective was to understand the host responses at different stages of virus infection at cellular level, which could provide some insight into the biology of virus-host interaction leading to the explanation that how virus infection modulates host cellular environment in A549 cells.

\section{Materials and methods} Viruses

Avian Influenza A (H5N1) virus, A/Chicken/India/WBNIV2664/2008 (WB-NIV2664) isolated from West Bengal (India) outbreak in 2008 [15] and reverse genetics modified H5N1 vaccine virus A/India/NIV/2006(H5N1)-PR8IBCDC-RG7 (IBCDC-RG7) were used in this study. The vaccine virus was constructed using modified hemagglutinin (HA) (deleting multiple basic amino acids at the cleavage site of $\mathrm{HA}$ ) and neuraminidase (NA) of A/Chicken/ India/NIV33487/06 (H5N1) in the background of A/PR/8/ 34 (H1N1) using reverse genetics technology at the Molecular Virology and Vaccine Laboratory, Influenza Division, Centers for Disease Control and Prevention, Atlanta. World Health Organization (WHO) has identified this strain as a $\mathrm{H} 5 \mathrm{~N} 1$ vaccine virus [16].

\section{Cell line}

Human lung carcinoma (A549) cells were maintained in Dulbecco's modified Eagle's tissue culture medium (Invitrogen Life Technologies, Carlsbad, CA, USA) containing $10 \%$ fetal calf serum, $100 \mathrm{units} / \mathrm{ml}$ penicillin, 100 units $/ \mathrm{ml}$ streptomycin in tissue culture flasks (Corning, USA) at $37^{\circ} \mathrm{C}$ in a $\mathrm{CO}_{2}$ incubator.

\section{Virus infection}

Monolayers of A549 cells at a concentration of $3 \times 10^{6}$ cells $/ \mathrm{ml}$ were infected with the viruses at a multiplicity of infection (MOI) of 3. After 1 hour the inoculum was removed; the cells were washed twice with phosphate buffer saline (PBS) and supplemented with growth media. For each virus four different sets of tissue culture flask were infected and harvested at four different time points. Mock infected cells at each time point served as controls. Infection of $\mathrm{H} 5 \mathrm{~N} 1$ viruses was performed in BSL-3+ facility.

\section{Preparation of Total Cellular RNA and microarray Hybridization}

Total RNA was extracted from the control and infected cells at 4, 8, 16 and 24 hpi using Trizol reagent (Invitrogen Life Technologies, Carlsbad, CA, USA) and purified by the RNeasy kit (Qiagen, Germany) following standard methodology. Amplification of RNA and indirect labeling of Cy-dye was done by Amino Allyl MessageAmp II aRNA amplification kit (Ambion, Austin, TX, USA) using manufacturer's instruction. One hundred nanograms of RNA from control and infected cells were used for the experiments. The RNA was reverse transcribed and amplified according to the manufacturer's protocol. The purified amino allyl aRNA was labeled with Cy3 and Cy5 (Amersham Biosciences, USA) for control and experimental samples respectively. Purified samples were lyophilized, resuspended in hybridization buffer (Pronto Universal Hybridization kit, Corning, USA) and hybridized on the Discover human chip (Arrayit Corporation, Sunnyvale, CA). Hybridization was carried out in a Hybstation (Genomic Solutions, Ann Arbor, MI) and the conditions used were $55^{\circ} \mathrm{C}$ for $6 \mathrm{~h}, 50^{\circ} \mathrm{C}$ for $6 \mathrm{~h}$, and $42^{\circ} \mathrm{C}$ for $6 \mathrm{~h}$. Scanning was performed at $5-\mathrm{mm}$ resolutions with the Scan array express (PerkinElmer, Waltham, MI). Grid alignment was done using gene annotation files and raw data were extracted into MS EXCEL.

\section{Data Analysis}

Data was analyzed using GENOWIZ Microarray and Pathway analysis tool (Ocimum Biosolutions, Hyderabad, India). Replicated values for genes were merged and median values of the expression ratios were considered for the dataset (2 slides per time point were used). Empty spots were removed by filtering. Dye bias was dealt with by applying loess normalization. Log transformation $(\log 2)$ was done to stabilize the variation in dataset and median centering was performed to bring down data distribution of dataset close to zero. In order to detect highly expressed genes, fold change analysis was done. Genes with 1.5 folds up/down-regulation were considered as differentially expressed at a p-value $<0.05$, Student's t-test. Functional classification of the genes was performed using gene ontology and pathway analysis.

\section{Quantitative RT-PCR analysis of host genes using SYBR Green I}

The differential expression data was validated by quantitative RT-PCR. One hundred nanograms of total RNA from control and infected A549 cells were used for quantitative RT-PCR analysis. Reaction was performed using the QuantiTect SYBR Green RT-PCR kit (Qiagen, Germany) according to the manufacturer's instructions. Reaction efficiency was calculated by using serial 10 -fold dilutions of the housekeeping gene- $\beta$-actin and sample 
genes. Reactions were carried out on an ABI 7300 realtime PCR system (Applied Biosystems, Foster City, CA, USA) and the thermal profile used was Stage $1: 50^{\circ} \mathrm{C}$ for $30 \mathrm{~min}$; Stage 2: $95^{\circ} \mathrm{C}$ for $15 \mathrm{~min}$; Stage 3: $94^{\circ} \mathrm{C}$ for 15 sec, $55^{\circ} \mathrm{C}$ for $30 \mathrm{sec}$; and $72^{\circ} \mathrm{C}$ for $30 \mathrm{sec}$, repeated for 30 cycles. Melting curve analysis was performed to verify product specificity. Reactions were performed in triplicates. All quantitations (threshold cycle [CT] values) were normalized to that of $\beta$-Actin to generate $\Delta \mathrm{CT}$, and the difference between the $\Delta C T$ value of the sample and that of the reference (uninfected sample) was calculated as $\Delta \Delta \mathrm{CT}$. The relative level of gene expression was expressed as $2^{-\Delta \Delta C T}$. Primer sequences for the genes of interest were designed using Primer Express 2.0 software (Applied Biosystems, Foster City, CA, USA). The primer sequences used in this study are as follows: JUN $F P 5^{\prime}$ TCGACATGGAGTCCCAGGA 3'; JUN RP 5' GGCGATTCTCTCCAGCTTCC $3{ }^{\prime} ;$ STAT1 FP 5' CCATCCTTTGGTACAACATGC 3'; STAT1 RP 5' TGCACATGGTGGAGTCAGG $3{ }^{\prime} ; C X C L 10 \quad F P \quad 5^{\prime}$ TTCAAGGAGTACCTCTCTCTAG 3'; CXCL10 RP 5' CTGGATTCAGACATCTCTTCTC 3'; CCL5 FP 5' TACCATGAAGGTCTCCGC 3'; CCL5 RP 5'GACAAAGACGACTGCTGG $3^{\prime} ; \beta$-ACTIN FP 5' CATGAAGTGT GACGTGGACATCC $3^{\prime} ; \beta$ - ACTIN RP 5' GCTGATCCACATCTGGAAGG 3'; BCL2 FP 5' GATGTCCAGCCAGCTGCACCTG $3^{\prime} ; B C L 2 R P 5^{\prime}$ CACAAAGGC ATCCCAGCCTCC $3^{\prime}$.

\section{Results}

Host gene expression response to HPAI-H5N1 (WBNIV2664) virus infection

The number of differentially expressed genes at different time-points after WB-NIV2664 infection is given in Table 1. Gene ontology analysis revealed that the genes involved in immune responses, translation and apoptosis were mostly up-regulated at all the time-points whereas genes involved in cell cycle and transcription were down-regulated. However, it was found that the number of genes was quantitatively different between the different time-points. A list of significantly up and down regulated genes at different post infection time points has been shown in Table S1 (Additional file 1). The 24 hpi time point showed maximum number of differentially expressed genes.

Cluster analysis of the differentially expressed genes was carried out using GENOWIZ software. K-means clustering and hierarchical clustering methods resulted in identification of 5 distinct patterns of gene expression at different time-points (Figure 1). A total of 189 genes were found common between all the time points. Expression pattern of most of the apoptotic genes was similar and formed a single cluster (Cluster 2 Figure 1). Apoptotic genes BAX, BAK1, TRADD and CASP1 were observed to be significantly up-regulated at 16 and 24 hpi but not at 4 and 8 hpi. Signaling molecules STAT1, IL15RA, GNBP1 were found to be up-regulated at all the time-points and showed a gradual increasing trend from 4 hpi to 24 hpi. Genes coding for ribosomal proteins and IRF1 (Interferon regulatory factor 1) were upregulated at 4, 8 and $16 \mathrm{hpi}$ but down-regulated at 24 hpi. Genes involved in cell cycle CDK4, CDK5, Cyclin E1, CKN2B, CDKN2D were down-regulated at all time-points post infection. Cytokines IL1, IL2- $\alpha$ and chemokines CXCL10, CCL5 were specifically upregulated at $16 \mathrm{hpi}$.

\section{Host gene expression response to RG modified H5N1 (IBCDC-RG7) virus infection}

The differentially expressed genes in cells infected with RG modified H5N1 (IBCDC-RG7) virus were involved in similar biological processes (GO analysis) as in response to H5N1 (WB-NIV2664) virus (Table 2). However, there was significant quantitative difference between the expression profiles of the two virus infections. Table S2 (Additional file 2) shows the list of significantly up and

Table 1 Summary of differentially expressed genes in response to infection with HPAI-H5N1 and RG modified H5N1 in A549 cell lines

\begin{tabular}{|c|c|c|c|c|}
\hline $\begin{array}{l}\text { Time- } \\
\text { points }\end{array}$ & $\begin{array}{l}\text { Genes qualifying the quality criteria in } \\
\text { replicated experiments }\end{array}$ & $\begin{array}{c}\text { Differentially expressed genes } \\
(+/-1.5 \text { folds, } p<0.05)\end{array}$ & $\begin{array}{l}\text { Up-regulated } \\
\text { genes }\end{array}$ & $\begin{array}{l}\text { Down-regulated } \\
\text { genes }\end{array}$ \\
\hline \multicolumn{5}{|c|}{ HPAI-H5N1 (A/Chicken/India/WB-NIV2664/2008) } \\
\hline $4 \mathrm{~h}$ & 253 & 40 & 15 & 25 \\
\hline $8 \mathrm{~h}$ & 208 & 24 & 13 & 11 \\
\hline $16 \mathrm{~h}$ & 254 & 101 & 53 & 48 \\
\hline $24 \mathrm{~h}$ & 309 & 111 & 53 & 58 \\
\hline \multicolumn{5}{|c|}{ RG Modified H5N1 (A/India/NIV/2006(H5N1)-PR8-IBCDC-RG7) } \\
\hline $4 \mathrm{~h}$ & 262 & 60 & 36 & 24 \\
\hline $8 \mathrm{~h}$ & 212 & 128 & 67 & 61 \\
\hline $16 \mathrm{~h}$ & 237 & 109 & 58 & 51 \\
\hline $24 \mathrm{~h}$ & 305 & 42 & 22 & 20 \\
\hline
\end{tabular}




\section{Genes: 189 Samples: 4}

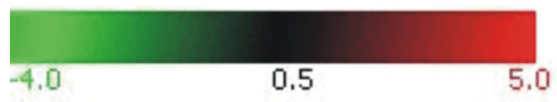

A
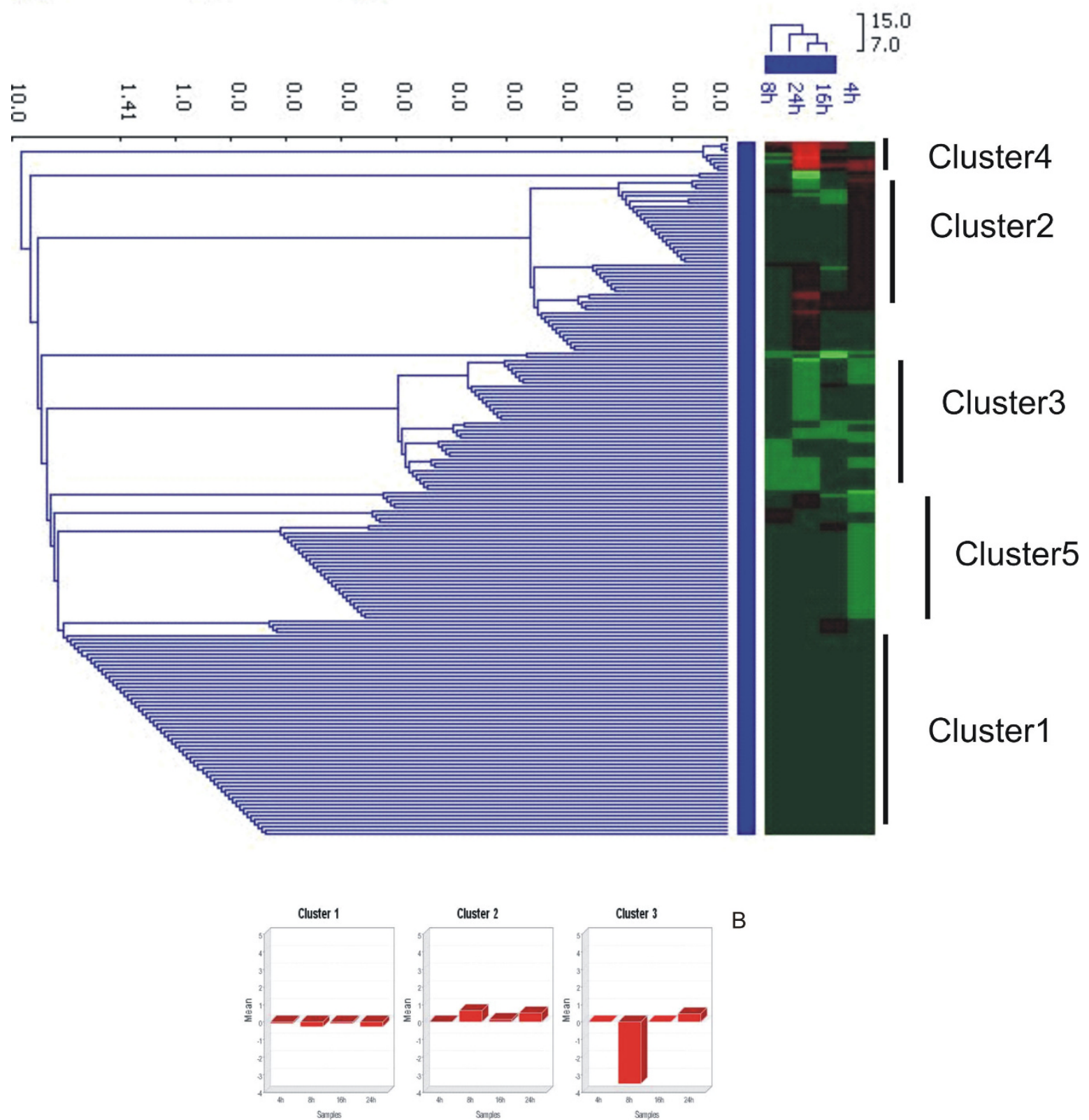

Cluster 3

B
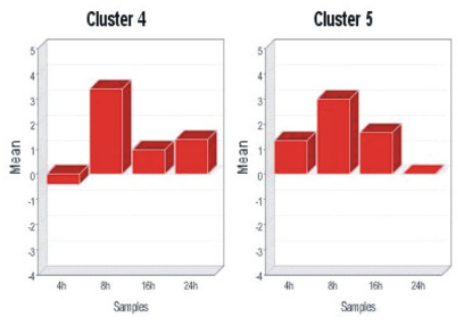

Figure 1 Hierarchical clustering (A) and k-means clustering (B) of differentially expressed genes of HPAI-H5N1 (A/Chicken/India/WBNIV2664/2008) infected A549 cells at different post-infection time points. Expression of genes with $p<0.05$ and fold change $>+/-1.5$ were considered as differentially expressed. Data presented are averaged gene expression changes for 2 different replicates for each time point. 
Table 2 Significantly enriched Gene Ontology terms in response to RG modified H5N1 and highly pathogenic H5N1 infection

\begin{tabular}{|c|c|c|}
\hline GO Term (Biological processes) & Gene Count & P-value \\
\hline \multicolumn{3}{|c|}{ RG modified H5N1 (A/India/NIV/2006(H5N1)-PR8-IBCDC-RG7) } \\
\hline GO:0042981 regulation of apoptosis & 45 & $4.45 \mathrm{E}-19$ \\
\hline GO:0042127 regulation of cell proliferation & 36 & $1.99 \mathrm{E}-12$ \\
\hline GO:0043066 negative regulation of apoptosis & 23 & $8.59 \mathrm{E}-11$ \\
\hline GO:0043065 positive regulation of apoptosis & 25 & $1.02 \mathrm{E}-10$ \\
\hline GO:0051726 regulation of cell cycle & 21 & 1.09E-09 \\
\hline GO:0006468 protein amino acid phosphorylation & 28 & 7.60E-09 \\
\hline GO:0045859 regulation of protein kinase activity & 19 & $7.55 \mathrm{E}-08$ \\
\hline GO:0019221 cytokine-mediated signaling pathway & 10 & $9.14 \mathrm{E}-08$ \\
\hline GO:0016477 cell migration & 16 & 5.87E-07 \\
\hline GO:0000086 G2/M transition of mitotic cell cycle & 6 & $3.15 \mathrm{E}-06$ \\
\hline GO:0051384 response to glucocorticoid stimulus & 8 & $2.90 \mathrm{E}-05$ \\
\hline GO:0043122 regulation of I-kappaB kinase/NF-kappaB cascade & 9 & $2.96 \mathrm{E}-05$ \\
\hline GO:0034330 cell junction organization & 7 & $4.44 \mathrm{E}-05$ \\
\hline GO:0006260 DNA replication & 11 & $6.29 \mathrm{E}-05$ \\
\hline GO:0046649 |ymphocyte activation & 11 & $9.26 \mathrm{E}-05$ \\
\hline GO:0045321 leukocyte activation & 12 & $1.01 \mathrm{E}-04$ \\
\hline \multicolumn{3}{|c|}{ HPAI-H5N1 (A/Chicken/India/WB-NIV2664/2008) } \\
\hline GO:0042981 regulation of apoptosis & 29 & $1.35 \mathrm{E}-13$ \\
\hline GO:0042127 regulation of cell proliferation & 26 & $2.83 \mathrm{E}-11$ \\
\hline GO:0043066 negative regulation of apoptosis & 17 & $1.27 \mathrm{E}-09$ \\
\hline GO:0006954 inflammatory response & 15 & $2.81 \mathrm{E}-08$ \\
\hline GO:0045597 positive regulation of cell differentiation & 13 & $3.55 \mathrm{E}-08$ \\
\hline GO:0043065 positive regulation of apoptosis & 16 & $1.38 \mathrm{E}-07$ \\
\hline GO:0001932 regulation of protein amino acid phosphorylation & 11 & $2.14 \mathrm{E}-07$ \\
\hline GO:0006952 defense response & 18 & $5.11 \mathrm{E}-07$ \\
\hline GO:0045321 leukocyte activation & 12 & 5.73E-07 \\
\hline GO:0006979 response to oxidative stress & 10 & $1.38 \mathrm{E}-06$ \\
\hline GO:0010740 positive regulation of protein kinase cascade & 10 & $1.61 \mathrm{E}-06$ \\
\hline GO:0051726 regulation of cell cycle & 13 & $1.87 \mathrm{E}-06$ \\
\hline GO:0030098 lymphocyte differentiation & 8 & $5.38 \mathrm{E}-06$ \\
\hline GO:0046649 /ymphocyte activation & 10 & $6.80 \mathrm{E}-06$ \\
\hline GO:0019221 cytokine-mediated signaling pathway & 7 & $6.83 \mathrm{E}-06$ \\
\hline GO:0048534 hemopoietic or lymphoid organ development & 11 & $8.57 \mathrm{E}-06$ \\
\hline GO:0006955 immune response & 17 & $1.10 \mathrm{E}-05$ \\
\hline GO:0030595 leukocyte chemotaxis & 5 & $1.02 \mathrm{E}-04$ \\
\hline GO:0042113 B cell activation & 6 & $1.48 \mathrm{E}-04$ \\
\hline
\end{tabular}

down regulated genes at different time point post infection. Contrastingly, genes coding for ribosomal proteins and other proteins involved in protein translation were down-regulated at early stages of (4 hpi) IBCDC-RG7 infection as compared to WB-NIV2664. Cell cycle regulator genes such as CDK5 and Cyclin B1 showed up- regulation only at 4 hpi but not at 8, 16 and 24 hpi. Apoptotic genes were significantly down-regulated at 16 hpi and 24 hpi. Genes involved in immune response such as IRF1, IL15R- $\alpha$, small inducible cytokine subfamily B (Cys-X-Cys), IL1- $\beta$, MHC, class1c were down-regulated at $4 \mathrm{hpi}$ and $16 \mathrm{hpi}$ (Figure 2). 

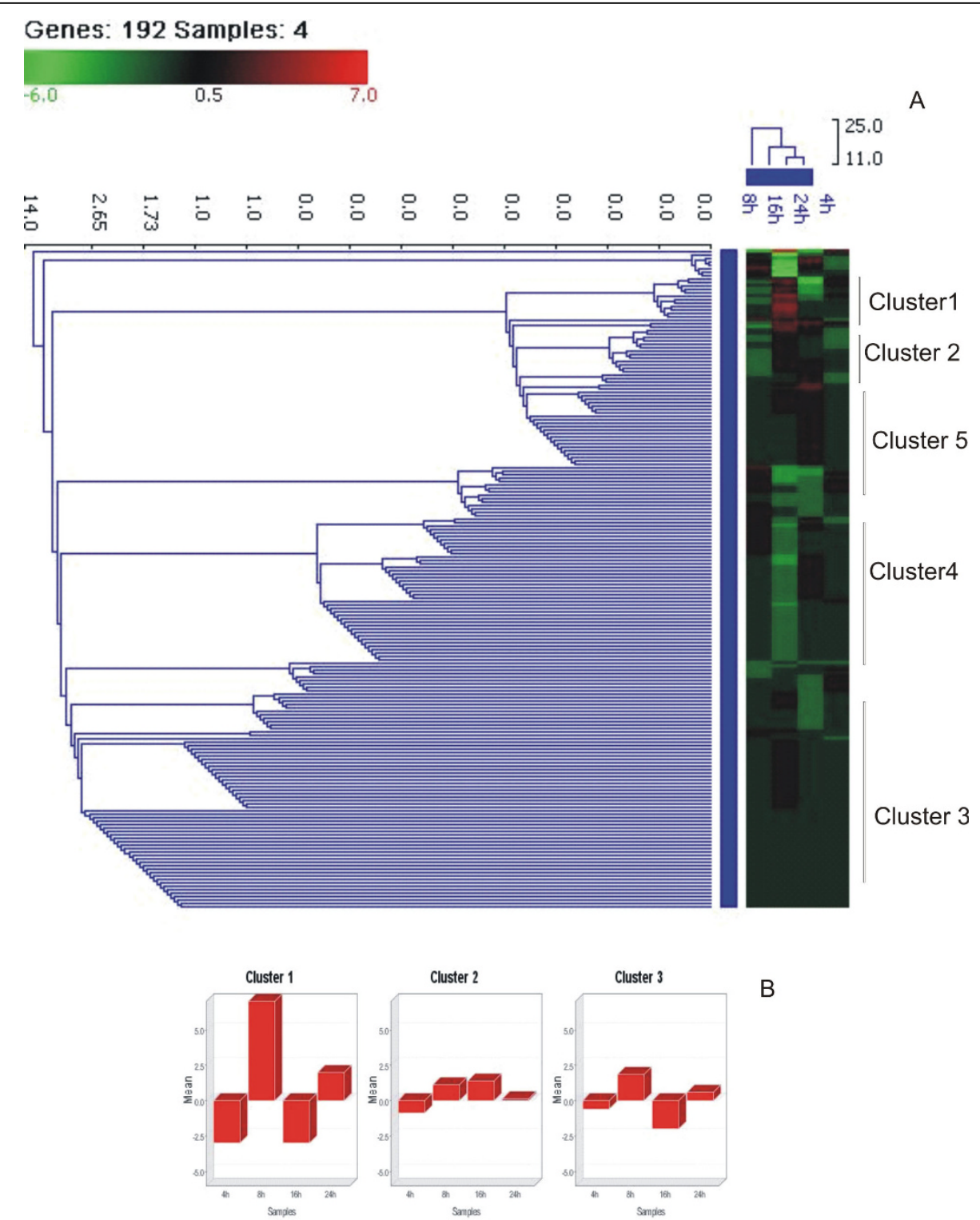

B

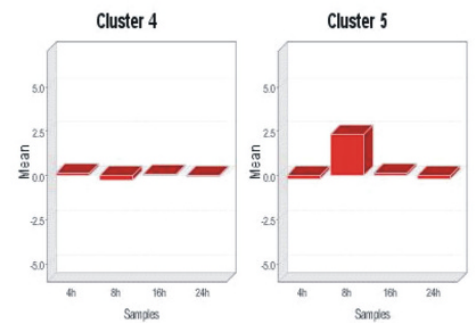

Figure 2 Hierarchical clustering (A) and k-means clustering (B) of differentially expressed genes of RG modified H5N1 (A/India/NIV/ 2006(H5N1)-PR8-IBCDC-RG7) infected A549 cells at different post-infection time points. Expression of genes with $p<0.05$ and fold change $>+/-1.5$ were considered as differentially expressed. Data presented are averaged gene expression changes for 2 different replicates.

Comparative analysis of host gene expression responses between HPAI-H5N1 and RG modified H5N1 virus infections

Gene expression data was compared separately at each post infection time points between the two virus infections (Figure 3). Significantly higher numbers of differentially expressed genes were observed at $16 \mathrm{hpi}$ (Figure 3). A total of 44 genes were found to be common between the two virus infections at 16 hpi. Out of them 8 genes were up-regulated and 8 genes were down- 


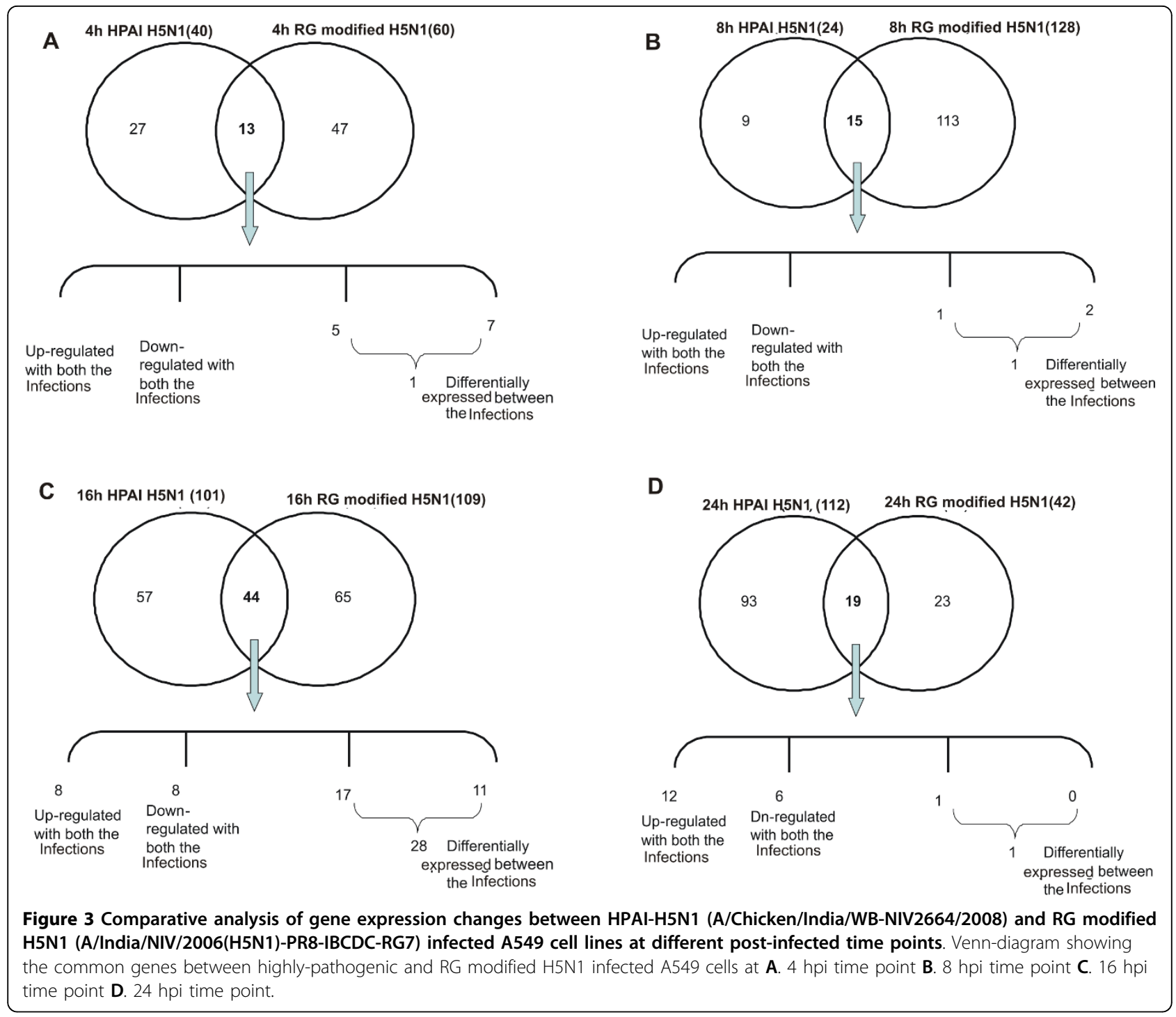

Table 3 Genes showing contrasting expression pattern between HPAI-H5N1 and RG modified H5N1 virus infection in A549 cells at 16 hpi

\begin{tabular}{ccc}
\hline GENES & HPAI-H5N1 (A/Chicken/India/WB-NIV2664/2008) & RG modified H5N1(A/India/NIV/2006(H5N1)-PR8-IBCDC-RG7) \\
\hline IL2R-alpha & 1.5 & -1.5 \\
\hline CXCL10 & 4.0 & -3.0 \\
\hline CCL5(RANTES) & 2.0 & -2.0 \\
\hline IL1-alpha & 2.0 & -2.0 \\
\hline IL15R-alpha & 2.6 & -2.8 \\
\hline JUN & 2.0 & -2.8 \\
\hline STAT1 & 3.2 & -2.0 \\
\hline FAS & 2.0 & -2.0 \\
\hline CyclinB1 & -2.0 & 2.0 \\
\hline
\end{tabular}




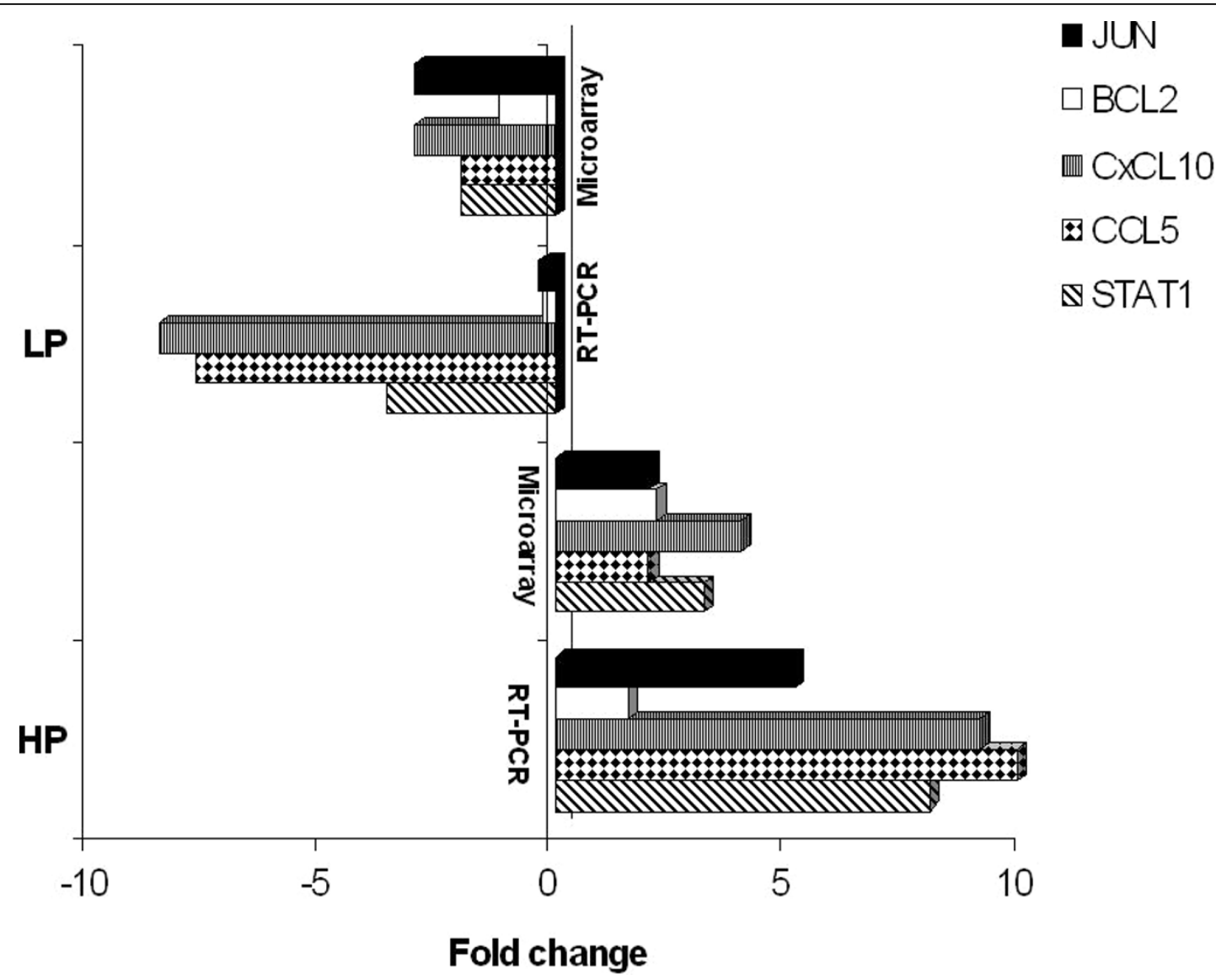

Figure 4 Validation of microarray data by real time PCR. Genes showing differential expression between HPAI-H5N1(HP) and RG modified H5N1(LP) virus infections at 16 hpi in A549 were selectively taken for RT-PCR analysis. The expressions of these genes were found to be matching with the microarray analysis.

regulated in response to both the virus infections. However, 28 genes were found to have differential expression pattern and were mainly involved in Cytokine-cytokine receptor interaction, Toll like-receptor mediated signaling and p53 signaling pathway [Figure S1 (Additional file 3) and Figure S2 (Additional file 4)]. Cytokines - CXCL10 and RANTES were up-regulated by 4 and 2 folds respectively in WB-NIV2664 infected cells but were downregulated by 3 and 2 folds respectively in response to infection with IBCDC-RG7 (Table 3). Transcription factors $\mathrm{v}$-JUN and NF- $\kappa \mathrm{B}$ were up-regulated in response to WB-NIV2664 infection but were down-regulated in infection with recombinant RG modified H5N1 (Table 3). STAT1, which plays a significant role in JAK-STAT signaling pathway and has been reported to be involved in host immune response to virus infections, was found to be differentially expressing between the two virus infections in our study. Surprisingly, cell cycle regulator Cyclin B1 was down-regulated in WB-NIV2664 infected cells but up-regulated in IBCDC-RG7 infected cells. Pathway analysis using KEGG [Kyoto Encyclopedia of genes and genome http://www.genome.jp/kegg/] tool reveled that these differences in expression profile between cells infected with two virus strains could manifest into differential cell cycle progression and immune response. Expression of selected genes was validated using Real-time PCR, which correlated with the microarray results (Figure 4).

\section{Discussion}

The present study demonstrates that the host gene expression responses to the highly pathogenic and recombinant $\mathrm{H} 5 \mathrm{~N} 1$ viruses were qualitatively similar but quantitatively different. The different time points of virus infection or different stages of virus life cycle played an important role in the host gene expression responses. Maximum differences in the host gene expression profile in response to both the virus infections were observed at $16 \mathrm{hpi}$. This time point is important because at this stage large number of completely assembled virus progeny particles inside the cells give rise to increased host immune responses [17]. 


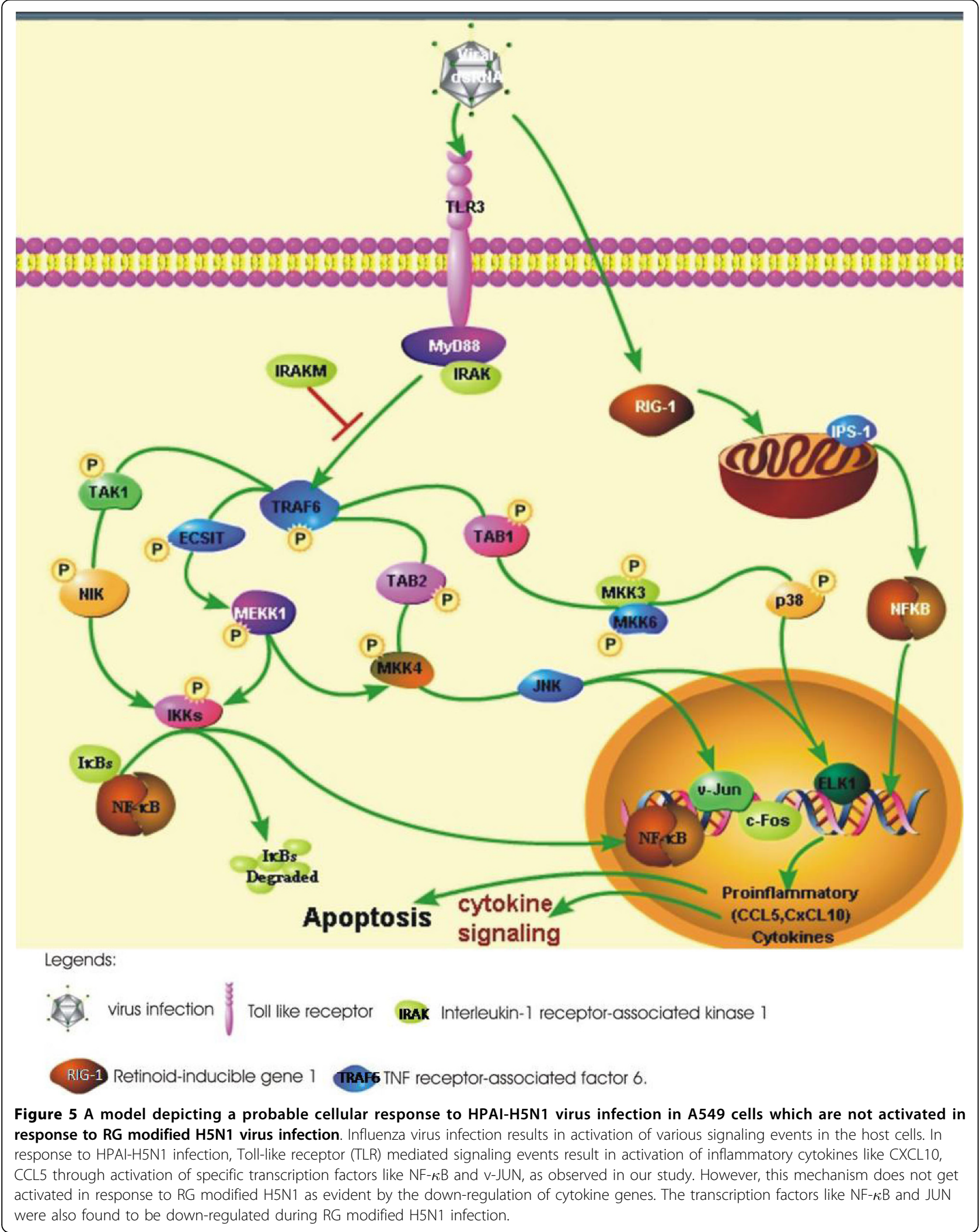


Contrasting differences in the expression of various genes between the two infections were found at $16 \mathrm{hpi}$.

It was interesting to observe significant increase in the expression of many cytokines and transcription factors in response to H5N1 (WB-NIV2664) virus infection but decrease in the expression of same genes in infection with RG modified H5N1 (IBCDC-RG7) at $16 \mathrm{hpi}$. These cytokines which mainly included IL2, IL1, CXCL10 and RANTES were reported to be involved in cytokinestorm in response to viral infection in humans $[18,19]$ and thus associated with $\mathrm{H} 5 \mathrm{~N} 1$ virulence.

In spite of overall similar cellular responses in both the infections, WB-NIV2664 was found to be a compelling inducer of cytokines CXCL10 and RANTES than IBCDC-RG-7. This differential expression of cytokines could result in a totally different host cellular response to both the virus infections. A hypothetical model showing probable cellular response to HPAI-H5N1 infection has been shown in figure 5. This type of signaling events might not get activated during RG modified H5N1 infection.

Differential expression of STAT1 in the two virus infections observed in our study also indicate higher cytokine mediated inflammatory responses in WBNIV2664 infection than the modified strain [20]. IRF-1 has been shown to activate STAT1 and regulates TNFrelated apoptosis-inducing ligand (TRAIL) in HIV-1infected macrophages [21]. The up- regulation of STAT1 in our experiments could be due to IRF1 mediated signaling. Up-regulation of NF- $\kappa \mathrm{B}$ and v-JUN observed in this study in response to WB-NIV2664 infection may provide necessary signals required for better virus entry and synthesis of viral proteins inside the cells $[22,23]$.

Cytokine dysregulation plays a major role in pathogenesis of influenza A (H5N1) viruses [5]. Studies on ferrets and nonhuman primates $[11,24]$ as well as on human macrophages [10] have clearly demonstrated the increased cytokine response during H5N1 infection.

The differences in the constitution of the internal genes between the subtypes of influenza viruses may possibly play an important role in differential host gene expression responses. Internal genes of $\mathrm{H} 5 \mathrm{~N} 1$ viruses, like non structural (NS1) and polymerase basic protein 2 (PB2) have been correlated with host immune responses and high pathogenicity [4,25]. Moreover, it is well established that presence of multiple basic amino acids in the cleavage site of HA is critical for high pathogenicity and systemic spread of H5N1 viruses [4]. Replacement of six internal genes with $\mathrm{A} / \mathrm{PR} / 8 / 34$ and absence of multibasic amino acids at the HA cleavage site of IBCDC-RG7, could be a vital reason for its inability to induce host cytokine response similar to WBNIV2664. Hence, our data supports that these host responses are probably driven by intrinsic differences of gene constitution of the H5N1 viruses.

Up-regulation of apoptotic genes like BAX, BAK1 in H5N1 (WB-NIV2664) but not in IBCDC-RG7 infection could be a part of cytokine mediated response [26]. The higher expression of apoptotic genes could explain higher amount of tissue damage observed in other studies during $\mathrm{H} 5 \mathrm{~N} 1$ infection. Among various viral factors, NS1 has been reported earlier to induce caspase-dependent apoptosis in human alveolar basal epithelial cells [25]. NS1 protein of H5N1 might have a role in enhancing expression of apoptotic factors leading to high virulence.

\section{Conclusion}

Thus, our findings show that HPAI-H5N1 is a better inducer of inflammation and cytokine mediated apoptosis compared to the RG modified H5N1 at a very specific stage of infection (16 hpi) which could explain its high pathogenicity. This study highlights the role played by the viral factors in inducing host defense mechanism by modulating host gene expression response.

\section{Additional material}

Additional file 1: Table S1. List of significantly up-regulated and down-regulated genes in A549 cells infected with HPAI-H5N1 at different post-infection time points. Genes showing increase or decrease in expression by $\geq 1.5$ folds (Significant, p-value $<0.05$ ) compared to controls at different post infection time points studied with HPAI-H5N1 have been enlisted.

Additional file 2: Table S2. List of significantly up- and downregulated genes in A549 cell lines infected with RG modified H5N1 at different post-infection time points. Genes showing increase or decrease in expression by $\geq 1.5$ folds (Significant, $p$-value $<0.05$ ) compared to controls at different post infection time points studied with RG modified H5N1 have been enlisted.

Additional file 3: Figure S1. Genes involved in chemokine \& cytokine mediated signaling in highly-pathogenic and RG modified H5N1 infected A549 cell lines (16 h post infection time point). Red arrow indicates expression in highly-pathogenic H5N1 infected A549 cells and Blue arrow indicates expression in RG modified H5N1 infected A549 cells. Up- arrow indicates up-regulation and down-arrow indicates downregulation.

Additional file 4: Figure S2. Genes involved in p53 signaling pathway in highly-pathogenic and RG modified H5N1 infected A549 cell lines ( $16 \mathrm{~h}$ post infection time point). Red arrow indicates expression in highly-pathogenic H5N1 infected A549 cells and Blue arrow indicates expression in RG modified H5N1 infected A549 cells. Up- arrow indicates up-regulation and down-arrow indicates down-regulation.

\section{Abbreviations}

HPAl: (highly pathogenic avian influenza virus); hpi: (hours post infection); aRNA: (amino allyl amplified RNA); RG modified: (Reverse genetics modified); GO: (gene ontology)

\section{Acknowledgements}

The authors are grateful to Dr. Ruben Donis, Chief, Molecular Virology and Vaccines Branch, Influenza Division, CDC, Atlanta, GA for his help and 
support to generate the recombinant vaccine strain of $\mathrm{H} 5 \mathrm{~N} 1$ and Dr. David Swayne, USDA, Athens, GA for testing this strain for pathogenesis. The authors are also thankful to Dr. Bhaskar Saha, NCCS, Pune, India for his helpful suggestions. The study was supported by the Indian Council of Medical Research, Government of India.

\section{Authors' contributions}

AKC and ACM conceived and designed the experiments. AKC, VCV, SM, RS and SDP performed the experiments. AKC, VCV, SM performed data analysis and bioinformatics studies. AKC, SM and ACM wrote the paper. All authors read and approved the final manuscript.

\section{Competing interests}

The authors declare that they have no competing interests.

Received: 7 July 2010 Accepted: 9 September 2010

Published: 9 September 2010

\section{References}

1. Cumulative number of confirmed human cases of avian influenza $A$ / (H5N1) reported to WHO. World Health Organization, 2010 Geneva, Switzerland. [http://www.who.int/csr/disease/avian_influenza/country/ cases_table_2010_05_06/en/index.html].

2. Osterholm T Michael: Preparing for the Next Pandemic. NEJM 2005, 352:18.

3. Thomas JK, Noppenberger J: Avian influenza: A review. Am J Health Syst Pharm 2007, 64:149-165.

4. Salomon RR, Franks J, Govorkova EA, Ilyushina NA, Yen H, Hulse-Post DJ, Humberd J, Trichet M, Rehg JE, Webby RJ, Webster RG, Hoffmann E: The polymerase complex genes contribute to the high virulence of the human H5N1 influenza virus isolate A/Vietnam/1203/04. JEM 2006, 203(3):689-697.

5. Peiris JS, Cheung $C Y$, Leung $C Y$, Nicholls JM: Innate immune responses to influenza A H5N1: friend or foe? Trends in Immunology 2009, 30(12):574-584.

6. Maines TR, Szretter KJ, Perrone L, Belser JA, Bright RA, Zeng H, Tumpey TM, Katz JM: Pathogenesis of emerging avian influenza viruses in mammals and the host innate immune response. Immunological Reviews 2008, 225(1):68-84.

7. Us D: Cytokine storm in avian influenza. Mikrobiyol Bul 2008, 42(2):365-80.

8. Reemers SS, Leenen D, Koerkamp MJ, Haarlem D, Haar P, Eden W, Vervelde L: Early host responses to avian influenza $A$ virus are prolonged and enhanced at transcriptional level depending on maturation of the immune system. Mol Immun 2010, 47:1675-1685.

9. Lee DC, Lau ASY: Avian influenza virus signaling: implications for the disease severity of H5N1 infection. Signal Transduction 2007, 7(1):64-80.

10. Lee SM, Gardy JL, Cheung CY, Cheung TK, Hui KP, Ip NY, Guan Y, Hancock RE, Peiris JSM: System-level comparison of host-responses elicited by avian $\mathrm{H} 5 \mathrm{~N} 1$ and seasonal $\mathrm{H} 1 \mathrm{~N} 1$ influenza viruses in primary human macrophages. PLoS One 2009, 4(12):e8072.

11. Cameron CM, Cameron MJ, Bermejo-Martin JF, Ran L, Xu L, Turner PV, Ran R, Danesh A, Fang Y, Chan PM, Mytle N, Sullivan TJ, Collins TL, Johnson MG, Medina JC, Rowe T, Kelvin DJ: Gene Expression Analysis of host innate immune responses during lethal $\mathrm{H} 5 \mathrm{~N} 1$ infection in ferrets. J Virol 2008, 82(22):11308-11317.

12. Matsukura S, Kokubu F, Kubo H, Tomita T, Tokunaga H, Kadukora M, Yamamoto T, Kuroiwa Y, Ohno T, Suzaki H, Adachi M: Expression of RANTES by normal airway epithelial cells after influenza virus $A$ infection. Ann J Respir Cell Mol Biol 1998, 18:255-264.

13. Salomon R, Hoffmann E, Webster RG: Inhibition of the cytokine response does not protect against lethal H5N1 influenza infection. PNAS 2007, 104(30):12479-12481

14. Nicholls JM, Chan MC, Chan WY, Wong HK, Cheung CY, et al: Tropism of avian influenza $\mathrm{A}(\mathrm{H} 5 \mathrm{~N} 1)$ in the upper and lower respiratory tract. Nat Med 2007, 13:147-149.

15. Chakrabarti AK, Pawar SD, Cherian SS, Koratkar SS, Jadhav SM, Pal B, Raut S, Thite V, Kode SS, Keng SS, Payyapilly BJ, Mullick J, Mishra AC: Characterization of the Influenza A H5N1 Viruses of the 2008-09 Outbreaks in India reveals a third introduction and possible endemicity. PLoS One 2009, 4(11):e7846.
16. Availability of a new recombinant $\mathrm{A}(\mathrm{H} 5 \mathrm{~N} 1)$ vaccine virus. World Health Organization, Geneva, Switzerland 2010 [http://www.who.int/csr/disease/ avian_influenza/H5N1 virusJuly/en/index.html].

17. Steel J, Lowen AC, Pena L, Angel M, Solo'rzano A, Albrecht R, Perez DR, García-Sastre A, Palese P: Live Attenuated Influenza Viruses Containing NS1 Truncations as Vaccine Candidates against H5N1 Highly Pathogenic Avian Influenza. J Virology 2009, 83(4):1742-1753.

18. Chan MCW, Cheung CY, Chui WH, Tsao SW, Nicholls JM, Chan YO, Chan RWY, Long HT, Poon LLM, Guan Y, Peiris JM: Proinflammatory cytokine responses induced by influenza $A(\mathrm{H} 5 \mathrm{~N} 1)$ viruses in primary human alveolar and bronchial epithelial cells. Respiratory Research 2005, 6:135-137

19. Kash JC, Basler CF, García-Sastre A, Carter V, Billharz R, Swayne DE, Ronald M, Przygodzki RM, Jeffery K, Taubenberger JK, Katze MG, Tumpey TM: Global Host Immune Response: Pathogenesis and Transcriptional Profiling of Type A Influenza Viruses Expressing the Hemagglutinin and Neuraminidase Genes from the 1918 Pandemic Virus. J Virology 2004, 78(17):9499-9511.

20. Seo JY, Kim DY, Lee YS, Ro JY: Cytokine production through PKC/p38 signaling pathways, not through JAK/STAT1 pathway, in mast cells stimulated with IFN gamma. Cytokine 2009, 46(1):51-60.

21. Huang $Y$, Walstrom A, Zhang L, Zhao Y, Cui M, Ye L, Zheng JC: Type I interferons and interferon regulatory factors regulate TNF-related apoptosis-inducing ligand (TRAIL) in HIV-1-infected macrophages. PLOS One 2009, 4(4):e5397.

22. Schmolke M, Dorothee Viemann D, Johannes Roth J, Ludwig S: Essential Impact of NF-kappaB Signaling on the H5N1 Influenza A Virus-Induced Transcriptome. J Immunol 2009, 183:5180-5189.

23. Konig R, Stertz S, Zhou Y, Inoue A, Hoffmann H, Bhattacharyya S, Alamares JG, Tscherne DM, Ortigoza MB, Liang Y, Gao Q, Andrews S, Bandyopadhyay $S$, Jesus PD, Tu BP, et al: Human host factors required for influenza virus replication. Nature 2009, 463(11):813-17.

24. Baskin CR, Bielefeldt-Ohmann H, Tumpey TM, Sabourin PJ, Long JP, et al: Early and sustained innate immune response defines pathology and death in nonhuman primates infected by highly pathogenic influenza virus. Proc Natl Acad Sci USA 2009, 106:3455-3460.

25. Zhang C, Yang Y, Zhou X, Liu X, Song H, He Y, Huang P: Highly pathogenic avian influenza $A$ virus H5N1 NS1 protein induces caspasedependent apoptosis in human alveolar basal epithelial cells. Virology Journal 2010, 7:51-54.

26. Uiprasertkul M, Kitphati R, Puthavathana P, Kriwong R, Kongchanagul A, Ungchusak K, Angkasekwinai S, Chokephaibulkit K, Srisook K, Vanprapar N, Auewarakul P: Apoptosis and Pathogenesis of Avian Influenza A (H5N1) Virus in Humans. Emerging Infectious diseases online 2007, 13(5):708-712 [http://www.cdc.gov/eid].

\section{doi:10.1186/1743-422X-7-219}

Cite this article as: Chakrabarti et al:: Host gene expression profiling in influenza A virus-infected lung epithelial (A549) cells: a comparative analysis between highly pathogenic and modified H5N1 viruses. Virology Journal 2010 7:219.

\section{Submit your next manuscript to BioMed Central and take full advantage of:}

- Convenient online submission

- Thorough peer review

- No space constraints or color figure charges

- Immediate publication on acceptance

- Inclusion in PubMed, CAS, Scopus and Google Scholar

- Research which is freely available for redistribution 